\title{
A PANDEMIA DO COVID-19 E A REPERCUSSÃO SOBRE O DIREITO À EDUCAÇÃO DE CRIANÇAS E ADOLESCENTES REFUGIADOS: UM CONVITE À APLICAÇÃO DO PRINCÍPIO DA FRATERNIDADE
}

\author{
Iranalha Carvalho de Souza ${ }^{1}$ \\ Veronica Verissimo Lopes ${ }^{2}$
}

DOI: https://doi.org/10.47306/978-65-88213-16-2.297-309

Sumário: 1 Introdução; $2 \mathrm{O}$ fenômeno da pandemia do novo coronavírus no contexto da infância e juventude; 3 A pandemia e a violação do direito educacional de crianças e adolescentes refugiados; 4 Fragmentos de fraternidade em vista da garantia do acesso à educação por crianças e adolescentes refugiados; 5 Considerações finais; Referências.

\section{INTRODUÇÃO}

A propagação do Covid-19 provocou uma intensa mudança global que afetou toda a estrutura social. Se anteriormente a esse período, a sociedade já enfrentava diversos problemas com as guerras, a destruição ambiental, a desigualdade econômica, os deslocamentos populacionais, dentre outras inúmeras adversidades, a pandemia do novo Coronavírus veio para potencializar todos esses males e gerar novos danos ao tecido social.

Nesse sentido, os povos refugiados, que já encontravam muitos obstáculos em suas trajetórias na busca por um lugar seguro para viver, se viram sem saída com o fechamento das fronteiras pelos países, devido à necessidade do isolamento social essencial ao controle da proliferação do vírus. Do mesmo modo, àqueles que já haviam fixado moradia em outras regiões também se depararam com grandes desafios de acesso a serviços básicos de saúde, segurança, assistência e educação.

Dentro desse contexto, enfatiza-se as consequências causadas especialmente às crianças e adolescentes refugiadas no que se refere ao acesso à educação escolar, tendo em vista que este

\footnotetext{
${ }^{1}$ Bacharela em Direito pelo Centro Universitário de João Pessoa (UNIPÊ); Pós-Graduanda em L.L.M. em Mediação, Gestão e Resolução de Conflitos pela Escola Superior de Advocacia (ESA-MG), Pós-graduanda em Direito e Processo Civil pela Escola Superior da Advocacia (ESA-PB). E-mail: iranalhac@gmail.com

${ }^{2}$ Bacharela em Direito pela Universidade Estadual da Paraíba (UEPB) e Pós-graduada em Direito Público pela Fundação Escola Superior do Ministério Público da Paraíba (FESMIP). E-mail: veripbjp@gmail.com
} 
grupo vem sofrendo sérios danos em decorrência da pandemia. É fato que não apenas os refugiados estão sendo afetados por essa problemática, uma vez que milhões de crianças estão distantes do espaço educacional (físico e/ou tecnológico) desde o início do isolamento social.

De acordo com um estudo realizado pelo Fundo das Nações Unidas pela Infância (UNICEF) e publicado em março de 2021, cerca de 168 milhões de crianças e adolescentes em idade escolar estão fora das escolas há mais de um ano devido ao seu fechamento, com ênfase na região da América Latina e do Caribe (UNICEF, 2021). Ainda, o mesmo estudo identificou que, pelo menos, um em cada três estudantes no mundo não conseguiu acessar o ensino a distância enquanto as escolas estavam fechadas.

Quando se explora a situação dos refugiados, o panorama se agrava, em virtude dos desafios adicionais enfrentados por esse grupo vulnerável, para o acesso escolar, como a xenofobia, a dificuldade de adaptação e aprendizado da língua local, a falta de equipamentos tecnológicos para aulas virtuais, acrescentando ainda a situação dos próprios educadores que nem sempre possuem uma formação e estrutura adequadas para atender as demandas desse público.

Desse modo, esse cenário revela uma clara violação a direitos humanos básicos da infância e da juventude, especialmente o direito à educação, fundamental ao desenvolvimento humano, social e econômico de um povo. Nesse caminho, o presente estudo pretende responder ao seguinte problema: em que medida a pandemia do Covid-19 afetou o direito educacional de crianças e adolescentes refugiados?

O método de investigação escolhido será o dedutivo, com o objetivo de analisar os principais efeitos sobre o direito à educação da infância e juventude refugiados no contexto pandêmico. Ainda, o caminho metodológico partirá de uma análise monográfica, com técnicas de pesquisa bibliográfica, documental, explorando a legislação internacional, a doutrina e materiais relativos à temática, buscando aprofundar a situação de vulnerabilidade a qual este grupo está exposta e extrair um sinal de esperança por meio da aplicação do princípio da fraternidade.

\section{O FENÔMENO DA PANDEMIA DO NOVO CORONAVÍRUS NO CONTEXTO DA INFÂNCIA E JUVENTUDE}

Decretada oficialmente pela Organização Mundial da Saúde (OMS) como pandemia em 11 de março de 2020, o novo Coronavírus anunciava uma assustadora época de incertezas para toda a humanidade e colocava em xeque a dignidade de cada pessoa ao expor à saúde humana a uma doença até então desconhecida pela ciência. O caos estava instaurado! O que preservar? 
Quem preservar? O que é prioridade? Quem é prioridade? Perecer pela doença ou pelo desemprego?

Esses e outros foram e são questionamentos constantes realizados no âmbito dos hospitais, entre as famílias, na esfera governamental, uma vez que, embora pudesse se constatar a necessidade de agir em coletividade para conter os avanços do vírus, também se fazia presente a preocupação com as inclinações individuais de categorias e grupos, em vista da satisfação dos interesses específicos.

É fato que qualquer pessoa está suscetível a contrair o Covid-19, dado que ele não escolhe cor, raça, gênero, espaço físico ou religião, inclusive, "no Ocidente, atingiu primeiramente os países mais ricos e, nesses, as pessoas que tiveram acesso a outros países que, via de regra, são as mais favorecidas" (ABRAHÃO, 2020, p.1), motivo pelo qual pôs em relevo a vulnerabilidade de toda a humanidade.

Todavia, embora o vírus possa ser democrático, a pandemia não é (LIMA, 2020), pois esta, a longo prazo, evidenciou a desigualdade estrutural que permeia a maior parte da população e reforçou o "Estado de Coisas Inconstitucional, [em razão] da violação generalizada de direitos fundamentais em relação à dignidade, à vida, à saúde, à integridade física e psíquica dos cidadãos brasileiros, considerada a condução da saúde pública durante a pandemia Covid19”, conforme assinalado pelo Ministro do Supremo Tribunal Federal, Marco Aurélio, no julgamento da Ação de Descumprimento de Preceito Fundamental nº 822/2021 (BRASIL, 2021, p.21)

Isso se manifesta, sobretudo, quando se analisa o tratamento precário dispensado pelo Estado na efetivação de direitos dos mais necessitados, a exemplo dos idosos, negros, pobres, das mulheres, indígenas, quilombolas e, conforme o objeto de estudo, das crianças e adolescentes. Não obstante esse grupo tenha sido o menos afetado em termos de mortalidade e acometimento da doença, ele sofreu danos colaterais que podem impactar negativamente a presente e futura geração.

Conforme a diretora executiva do UNICEF, Henrietta Fore (UNICEF, 2021, p.1), "um ano após o início da pandemia de Covid-19, o progresso retrocedeu em praticamente todos os principais indicadores relacionados à infância", tais como o aumento da pobreza infantil, déficit na escolaridade, aumento dos casamentos infantis, saúde mental e física, desnutrição e falta de acesso à infraestrutura sanitária necessária à prevenção do vírus.

Desse modo, percebe-se a necessidade de discutir meios para assegurar a proteção da população infantoadolescente, pois, conforme afirma Patto (2013, p.17) "Quem mais precisa ser defendido é quem não é capaz de se defender por si próprio. É nesses casos que vale a 
advertência evangélica sobre o amor ao "mais pequeno dos meus irmãos"', despertando para o dever de proteção à vida humana desse grupo vulnerável.

\section{A PANDEMIA E A VIOLAÇÃO DO DIREITO EDUCACIONAL DE CRIANÇAS E ADOLESCENTES REFUGIADOS}

A circulação de pessoas entre regiões existe desde os primórdios da história humana, mas a internacionalização do instituto do refúgio, como é conhecido hoje, ganha relevo em meio aos grandes conflitos mundiais do século XX. Inicialmente, tem-se os prejuízos causados no contexto da Primeira Guerra Mundial, que levou muitos europeus à condição de refugiados.

Posteriormente, a história se repete, com a instauração da Segunda Guerra Mundial, gerando um intenso fluxo migratório de pessoas que buscavam fugir da destruição provocada pelo conflito armado. Desde então, a humanidade não foi mais a mesma, uma vez que se fazia urgente e necessária a estruturação da política internacional para o acolhimento dos novos povos nos diferentes países.

Continuamente, surgiram conflitos de todos os gêneros, que continuam a estimular a evasão de muitos indivíduos ao redor do globo, podendo mencionar a guerra civil da Síria, as crises na África Subsaariana, na Venezuela, no Haiti, dentre outras, que constantemente afetam milhões de pessoas.

Após essa breve análise histórica, é necessário compreender o que exatamente constitui o instituto do refúgio, fazendo as devidas diferenciações em relação à migração. No que se refere ao primeiro, trata-se de um conceito que vem sendo construído e adaptado ao longo das épocas, mas de acordo com o Alto Comissariado das Nações para os Refugiados (ACNUR, 2020,p.1), refugiado:

São pessoas que estão fora de seu país de origem devido a fundados temores de perseguição relacionados a questões de raça, religião, nacionalidade, pertencimento a um determinado grupo social ou opinião política, como também devido à grave $\mathrm{e}$ generalizada violação de direitos humanos e conflitos armados.

Conforme analisado, trata-se de uma ação que envolve fatores alheios à vontade humana, visto que comumente os refugiados não desejam sair de seu país de origem, mas são forçados a tanto por razões que não conseguem controlar, como as mencionadas acima. É justamente nesse ponto, a voluntariedade, que está a distinção em relação aos migrantes (imigrantes e emigrantes), porque estes, via de regra, se deslocam de seus países espontaneamente, seja em busca de melhor qualidade de vida, por motivos de estudo, para reunião familiar ou por outras razões. É relevante fazer tal diferenciação, visto que para cada grupo há várias particularidades no que se refere à proteção jurídica nacional e internacional. 
Outrossim, é pertinente mencionar a legislação que confere tutela aos refugiados. Em nível internacional, os principais instrumentos jurídicos são a Convenção relativa ao Estatuto dos Refugiados de 1951, o Protocolo relativo ao Estatuto dos Refugiados e a Declaração de Cartagena, de 1984. No que concerne ao arcabouço normativo brasileiro, pode-se mencionar a Constituição Federal de 1988, o Estatuto dos Refugiados (Lei n. 9.474/1997), cabendo acrescentar a Lei n. 13.445/2017 e a Lei n. 13.684/2018, ambas referentes à proteção dos migrantes.

Atualmente, cerca de metade da população mundial de refugiados é composta por crianças menores de dezoito anos (FERREIRA, 2020, p.1). Esse dado desperta preocupação nos diversos órgãos de proteção da infância, uma vez que põe em questão qual tem sido o tratamento concedido em termos de tutela dos infantoadolescentes pelos Estados e sociedade civil.

É verdade que há muito tempo as crianças deixaram de ser vistas como objeto das ações humanas e assumiram a condição de sujeitos de direitos protagonistas da construção de um mundo renovado. A evidência disso é que a Convenção Internacional sobre os Direitos das Crianças (CDC) é o instrumento de direitos humanos mais aceito dos últimos tempos, sendo ratificada por 196 países, entre eles, o Brasil.

A partir da referida convenção, emerge a Doutrina da Proteção Integral, cujo cerne é a concessão de uma proteção especial à infância e adolescência. Nesse sentido, assevera Veronese (2019, p. 21, grifo nosso):

\footnotetext{
A Doutrina da Proteção Integral reconhece os direitos das crianças e adolescentes, compreendendo-os como sujeitos de direitos, sujeitos humanos em processo de desenvolvimentos, construtores, portanto, de um protagonismo, que se opõe a ideia civilista da "capacidade/incapacidade". Ao situá-los como sujeitos, redimensiona conceitos tradicionais, em uma necessária crítica ao adultocentrismo, que menorizava e coisificava a infância.
}

Diante do exposto, constata-se a relevância dessa doutrina para a criação de uma nova perspectiva em relação ao tratamento que a humanidade dispensava até então a essas pessoas. No entanto, é necessário evoluir em muitos aspectos, pois ainda há uma grande maculação dos direitos infantojuvenis.

Do ponto de vista das crianças e adolescentes refugiados, há uma alta exposição da vida humana a qual esse grupo se submete, visto que durante o decurso dos deslocamentos poderá haver as mais variadas espécies de inseguranças provocadas pelo tráfico, violência (física, sexual, psicológica), exploração, abusos, dentre outros.

Ademais, quando situados nos países de abrigo, é complexa a integração, adaptação e acolhimento na realidade local, sobretudo devido à ausência de condições dignas relativas a 
direitos sociais básicos. Os desafios se exprimem de diversos modos, com a dificuldade de empregabilidade pelas famílias; instalações residenciais deficitárias, sem acesso a saneamento básico; a morosidade com a regulamentação interna; as barreiras linguísticas; os obstáculos para o acesso à tecnologia, além da "intolerância, xenofobia, agressão, tensões e conflitos nacionais e étnicos" (UNESCO, 2019, p.7).

Todos esses entraves refletem negativamente no acesso educacional de crianças e adolescentes. De acordo com a ACNUR, uma criança refugiada tem duas vezes mais chances de estar fora das escolas do que uma criança não refugiada (ACNUR, 2020). Além disso, dados divulgados pelo documento de Proteção do Direito à Educação dos Refugiados, elaborado pela Organização das Nações Unidas para a Educação, a Ciência e a Cultura (UNESCO) apontam que em torno de $47 \%$ de crianças refugiadas não foram matriculadas na educação primária, bem como $84 \%$ dos adolescentes refugiados entre quinze a dezessete anos, não compareceram a educação secundária em 2016 (UNESCO, 2019).

Com a pandemia, a previsão é que esse número aumente. Ainda, se não forem tomadas as devidas medidas para a inserção de crianças e adolescentes refugiados no espaço educacional, há riscos de elas não poderem retornar mais para as escolas (ACNUR, 2020). Atualmente, um dos maiores desafios é com o ensino à distância, potencializado pela ausência de aparelhos eletrônicos, dados móveis e dificuldade com a língua. Acrescente-se a essa conjuntura, a condição a qual milhares de meninas em situação de refúgio se encontram.

Isso porque se o acesso à educação para elas já era deficitário antes da pandemia, a situação piorou de forma drástica. "Ao analisar os dados do ACNUR sobre matrícula escolar, o Fundo Malala estimou que metade de todas as meninas refugiadas na escola não retornará quando as salas de aula forem reabertas em setembro" (ACNUR, p.5, tradução nossa), motivo pelo qual essa realidade desvela também um problema de desigualdade de gênero, visto que longe das escolas, as mesmas são mais propensas à contração de casamentos infantis, gravidez precoce e violência doméstica, e dificilmente conseguirão se profissionalizar e adquirir independência financeira.

Em virtude das violações mencionadas acima, tem-se a desobediência a inúmeros dispositivos normativos internacionais de tutela do direito à educação, visto que este encontrase regulamentado no artigo 26 (1), (2) e (3) da Declaração Universal de Direitos Humanos (DUDH), artigo 28 da CDC e nos seus correlatos, artigo 22 da Convenção Relativa ao Estatuto dos Refugiados e demais legislações pertinentes ao tema.

No âmbito do ordenamento jurídico brasileiro, a garantia do direito fundamental à educação está prevista no Art. 205 e se estende também aos povos refugiados no Brasil. Nesse 
caminho, o Conselho Nacional de Educação aprovou a resolução n. 1\%2020, para assegurar o “direito de matrícula de crianças e adolescentes migrantes refugiados, apátridas e solicitantes de refúgio no sistema público de ensino brasileiro" (BRASIL, 2020).

Por todo o exposto, percebe-se o extenso arcabouço normativo de proteção da infância, que garante o acesso à educação. Mas não basta apenas criar leis e mais leis, é necessário traçar os meios para efetivá-las. Bobbio (2002, p.17, grifo nosso), em A Era Dos Direitos, assinala:

O problema grave de nosso tempo, com relação aos direitos do homem, não era mais o de fundamentá-los, e sim o de protegê-los [...] Com efeito, o problema que temos diante de nós não é filosófico, mas jurídico e, num sentido mais amplo, político. Não se trata de saber quais e quantos são esses direitos, qual é sua natureza e seu fundamento, se são direitos naturais ou históricos, absolutos ou relativos, mas sim qual é o modo mais seguro para garanti-los, para impedir que, apesar das solenes declarações, eles sejam continuamente violados.

Desse modo, identifica-se que falta uma atitude propositiva, permeada pelo espírito de fraternidade na atuação política, social e jurídica, para desenvolver caminhos concretos de efetivação dos direitos fundamentais da pessoa humana. Assim, não basta que os países ratifiquem os tratados internacionais de proteção da infância ou desenvolvam legislações nacionais avançadas, mas é imprescindível honrar com os seus compromissos, uma vez que o que está em risco é a vida de milhares de crianças em situação de vulnerabilidade.

Ademais, sem esse comprometimento, não será possível alcançar os dezessete Objetivos de Desenvolvimento Sustentável (ODS) propostos pela Agenda 2030, fundamentalmente o objetivo $\mathrm{n}^{\mathrm{0}} 4$, que propõe "Assegurar a educação inclusiva e equitativa de qualidade, e promover oportunidades de aprendizagem ao longo da vida para todos" (AGENDA 2030, 2021, p.1). Tal realidade é um imperativo que deve ser assumido por todos.

\section{FRAGMENTOS DE FRATERNIDADE EM VISTA DA GARANTIA DO ACESSO À EDUCAÇÃO POR CRIANÇAS E ADOLESCENTES REFUGIADOS}

Não obstante os caminhos para o acesso à educação pela população infantoadolescente pareçam complexos e distantes, sobretudo nessa época pandêmica, é possível vislumbrar raios de esperança manifestados pelo sentimento de fraternidade que estimula famílias, comunidades e Governos a agirem em função do bem comum da infância.

Isso se dá porque acontecimentos como a pandemia do novo Coronavírus não demonstram apenas o lado obscuro das pessoas, mas revelam também a beleza que nasce a partir do reconhecimento do outro enquanto ser humano e da identificação fraterna. Nessa 
dimensão, discorre o Papa Francisco no documento (Encíclica Fratelli Tutti) ${ }^{3}$ sobre a Fraternidade e a Amizade Social (2020, p.9):

É verdade que uma tragédia global como a pandemia do Covid-19 despertou, por algum tempo, a consciência de sermos uma comunidade mundial que viaja no mesmo barco, onde o mal de um prejudica a todos. Recordamo-nos de que ninguém se salva sozinho, que só é possível salvar-nos juntos. Por isso, «a tempestade - dizia eu desmascara a nossa vulnerabilidade e deixa a descoberto as falsas e supérfluas seguranças com que construímos os nossos programas, os nossos projetos, os nossos hábitos e prioridades. (...) Com a tempestade, caiu a maquilhagem dos estereótipos com que mascaramos o nosso "eu" sempre preocupado com a própria imagem; e ficou a descoberto, uma vez mais, esta (abençoada) pertença comum a que não nos podemos subtrair: a pertença como irmãos.

Diante disso, constata-se que não é possível passar por essa experiência alimentando perspectivas individualistas, mas deve vir em evidência o senso de coletividade que desperta em cada um o desejo de colaboração mútua. É com esse espírito altruístico que diversos atores sociais (Governo, comunidades, famílias e pessoas) estão buscando meios para amenizar os impactos causados nos estudos de milhares de crianças e adolescentes.

Um relatório produzido pela ACNUR recolheu experiências realizadas em doze países (Chade, Etiópia, Iraque, Jordânia, Quênia, Líbano, Paquistão, Ruanda, Sudão do Sul, Tanzânia, Turquia, Uganda), na qual "refugiados e comunidades anfitriãs, professores, setor privado parceiros, autoridades nacionais e locais, inovadores e agências humanitárias encontraram inúmeras maneiras de manter a educação em andamento em face da pandemia" (ACNUR, 2020, p.3, tradução nossa).

Não será possível aprofundar todas nesse estudo, mas a título de exemplo pode-se mencionar o trabalho desenvolvido por uma professora, Amina Hassan, que dava aulas em uma escola num campo de refugiados no Quênia e, que depois da decretação do isolamento social, passou a ministrar o ensino via rádio em uma estação comunitária chamada Rádio Gargaar, cuja tradução é "ajuda" ou "assistência social" em somali. A intenção dela foi a de preservar ao máximo a continuidade dos estudos dessa população, que já é deficitária e, por isso, não mediu esforços para encontrar uma alternativa eficiente.

No Egito, o Governo vinha há alguns anos desenvolvendo estratégias de ensino à distância, oportunidade em que cada aluno de escola pública (incluindo o acesso pelos migrantes e refugiados) recebeu um tablet para auxílio nos estudos. Com a chegada do Covid19, esse sistema de ensino foi aprimorado e ficou mais simples a adequação ao novo modo de ensino-aprendizado. Tal projeto está sendo atuado conjuntamente com outras organizações e

\footnotetext{
${ }^{3}$ Todos irmãos.
} 
reflete um avanço em relação a outros países que caminham a curtos passos nessa era de hiperglobalização.

Outro exemplo inspirador é o da professora brasileira, Jennifer Barros, que trabalha em um abrigo de refugiados provenientes da Venezuela, na cidade de Boa Vista, em Roraima. Depois que iniciou a pandemia, ela buscou meios inovadores para permanecer ministrando aulas, seguindo todos os protocolos de segurança e, junto com outros professores, decidiram fazer reforço escolar uma vez por semana, em diversas disciplinas, especialmente em português.

Diante desse contexto, visualiza-se um conjunto de atividades desenvolvidas por diferentes atores, em diferentes localidades do mundo, mas com o único propósito: assegurar o acesso educacional às crianças e adolescentes refugiados.

Essas experiências são expressões, ainda que inconscientes, de uma nova proposta de governo, intitulada de Cogovernança, cuja ideia principal é a construção de um "governo participativo, que almeja um elevado nível de colaboração intersubjetiva e multissetorial na construção das políticas públicas" (CO-GOVERNANCE, 2021, p.1). Ainda, visa "conceber coletivamente uma visão social e comum e, em seguida, agir em corresponsabilidade". (COGOVERNANCE, 2021, p.1). Tal modelo, portanto, é um convite ao exercício da cidadania ativa, objetivando colocar no centro das ações o cuidado coletivo e o bem comum.

Em vista disso, é possível extrair que a era moderna exige cada vez da humanidade a adoção de um novo estilo de vida, que transpõe visões autocêntricas e individualistas e busca encontrar os pontos de convergência entre os povos, para superar todas as formas de divisões e elaborar estratégias coletivas que valorizem a promoção dos direitos humanos.

Esse novo modo de agir passa pela necessária inserção do princípio da fraternidade nas relações. Fraternidade, que na gênese da palavra remete ao reconhecimento do outro como irmão, trata-se da união entre os seres humanos, baseada no respeito à dignidade comum que existe em cada pessoa e que nos torna "livres e iguais" (informação verbal) 4 .

Baggio sabiamente irá afirmar que "quando uma sociedade já não tem mais nada, ela sempre recomeça pela fraternidade" (informação verbal) ${ }^{5}$. Assim, diante desse contexto conturbado no qual a humanidade se encontra, em que se visualiza tantas dores sociais, com a destruição em massa provocada pela Covid-19, as divisões, as guerras; onde há rotineiramente o desrespeito aos direitos fundamentais de crianças e adolescentes refugiados, é por meio da

\footnotetext{
${ }^{4}$ Fala do professor Antônio Maria Baggio proferida na palestra sobre Fraternidade, em ocasião da Escola de Brancos e Assistentes Gen 2 do Movimento dos Focolares

${ }^{5}$ Fala do professor Antônio Maria Baggio proferida na palestra sobre Fraternidade, em ocasião da Escola de Brancos e Assistentes Gen 2 do Movimento dos Focolares
} 
observância do princípio da fraternidade que será possível o restabelecimento da harmonia social. E o como atuar essa realidade se traduz, essencialmente, na vivência do amor fraterno.

Por fim, é relevante acrescentar a importância da cooperação internacional para o efetivo atendimento aos direitos dos infantoadolescentes refugiados. Desse modo, não é suficiente a intenção de assegurar tais garantias, mas é necessário estabelecer ações efetivas que beneficiem esse grupo concretamente, além de consolidar um esquema de lealdade diante das abstratas promessas de colaboração recíproca.

Nesse aspecto, tais comportamentos podem e devêm ser atuados à luz da dinâmica da fraternidade, pois, a partir disso, desenvolve-se o respeito natural à pátria do outro, de modo a permitir o acolhimento de todos, especialmente nas situações de dificuldades, sem quaisquer preconceitos ou juízo de valores, mas tendo em conta o enriquecimento mútuo que nasce da convivência entre os povos diversos.

Nessa dimensão, afirma o Papa Francisco (2020, p.35):

A chegada de pessoas diferentes, que provêm dum contexto vital e cultural distinto, transforma-se num dom, porque «as histórias dos migrantes são histórias também de encontro entre pessoas e entre culturas: para as comunidades e as sociedades de chegada são uma oportunidade de enriquecimento e desenvolvimento humano integral para todos.

Sobre o tema, escreve Chiara Lubich

A mais alta dignidade para a humanidade seria, na realidade, que não se sentisse um conjunto de povos frequentemente em conflito entre si, mas que fosse, pelo amor recíproco, um único povo, enriquecido pela diversidade de cada um e, por isso, guardião da unidade entre as diferentes identidades. (Lubich, 2004, tradução nossa)

Diante do exposto, depreende-se que a introdução de povos e culturas distintas em uma sociedade vem para agregar a riqueza particular que esta possui e dá a possibilidade de um novo desenvolvimento, sem necessariamente perder as características que a individualiza, dado que também é relevante a conservação cultural de cada lugar.

\section{CONSIDERAÇÕES FINAIS}

O presente trabalho possibilitou fazer uma análise do direito à educação de crianças e adolescentes em situação de refúgio no contexto pandêmico, na qual é possível identificar o quanto esse período vem sendo decisivo para o futuro educacional dessa população.

Para tanto, foi realizado um exame sobre a atual conjuntura mundial e identificado como o Covid-19 vem atingindo de forma maciça as pessoas que se encontram em situação de vulnerabilidade, destacando-se o desrespeito aos direitos humanos fundamentais da infância e juventude. 
Ao longo do ensaio, foi feita uma análise histórica, acompanhada da definição do instituto do refúgio e a sua diferenciação em relação à migração. Ademais, foi apresentada as principais legislações protetivas dos refugiados em âmbito nacional e internacional. Nesse diapasão, apontou-se os danos sofridos por esse grupo em virtude dos deslocamentos populacionais e a repercussão sobre a educação.

Posteriormente, fora abordado a aplicação do princípio da fraternidade como um vetor para a atuação política, social e jurídica no que se refere à proteção dos infantoadolescentes refugiados. Dentro disso, se apresentou algumas experiências vivenciadas por diferentes atores sociais a fim de assegurar o acesso aos estudos em tempos pandêmicos. Ações estas que revelam a importância do atuar em coletividade para a concretização da justiça social.

Portanto, ao buscar responder o problema de pesquisa: em que medida a pandemia do Covid-19 afetou o direito educacional de crianças e adolescentes refugiados? Constatou-se que a pandemia fragilizou ainda mais o direito educacional desse público, tendo em vista que potencializou a e gerou inúmeras dificuldades para o seu acesso devido à falta de uma estrutura adequada (em todos os âmbitos) para a oferta do ensino.

Assim, tem-se que proteger os direitos humanos educacionais de crianças e adolescentes em situação de refúgio, sobretudo nesse período, constitui um imperativo que deve ser seguido por todos, pelos Estados, Governos, organizações humanitárias, pela sociedade civil, individualmente, uma vez que a não garantir implica no prejuízo do futuro de toda uma geração.

Conforme observado, é fundamental a positivação de normas protetivas, mas é necessário também o desenvolvimento de meios para a sua efetiva execução. Para tanto, é imprescindível agir em cooperação e com um espírito de fraternidade, para se concentrar, principalmente, em aquilo que une os indivíduos em vez de focar no que os separa.

Saliente-se que não se. trata de atenuar os obstáculos burocráticos, econômicos e sociais que envolvem todo esse processo, mas de compreender que se agirmos enquanto corpo social será possível superar os desafios para a integração, adaptação e acolhimento dos refugiados, e encontrar caminhos inovadores que beneficiem a todos e assegurar, especialmente, a construção de um futuro promissor para toda a humanidade, por meio do acesso educacional.

\section{REFERÊNCIAS}

ABRAHÃO, Jorge. Um vírus democrático que evidencia a fragilidade da democracia. 01.04. 2020.Disponível em:https://www.nossasaopaulo.org.br/2020/04/01/umvirusdemocratico-que-evidencia-a-fragilidade-da-democracia/. Acesso em: 11 jul. 2021. 
ACNUR. Refugiados. Disponível em: https://www.acnur.org/portugues/quemajudamos/refugiados/. Acesso em: 12 jul. 2021.

BOBBIO, Norberto. A era dos direitos. Rio de Janeiro: Elsevier, 2004. 96 p. Disponível em: https://edisciplinas.usp.br/pluginfile.php/297730/mod_resource/content/0/norbertobobbio-aera-dos-direitos.pdf. Acesso em: 12 jul. 2021.

BRASIL. Resolução n. 1, de 13 de novembro de 2020. Dispõe sobre o direito de matrícula de crianças e adolescentes migrantes, refugiados, apátridas e solicitantes de refúgio no sistema público de ensino brasileiro. Diário Oficial da União, Brasília, DF, 16 novembro 2020. Disponível em: https://www.in.gov.br/en/web/dou/-/resolucao-n-1-de-13-de-novembro-de2020-288317152. Acesso em: 12 jul. 2021.

BRASIL. Supremo Tribunal Federal. ADPF n. 822/DF. Requerente: CENTRAL ÚNICA DOS TRABALHADORES-CUT e outros (CF 103, IX). Requerido: Supremo Tribunal Federal. Relator: Ministro Marco Aurélio. Art. $6^{\circ}$; art. 23, inciso II; art. 24, inciso XII; art. 194; art. 196; art. 197; art. 198; art. 5º caput; art. 227; art. 230, da Constituição Federal de 1988. Brasília, 08 de abril de 2021. Disponível

em:http://portal.stf.jus.br/processos/detalhe.asp?incidente=6150239. Acesso em: 12 jul. 2021 .

CO-GOVERNANCE. Co-governance. Disponível em: https://pt.co-governance.org/. Acesso em 13 jul.2021.

FERREIRA, Alana. Crianças representam cerca de metade do número de refugiados do mundo. 12.10.2020. Disponível em: https://www.acnur.org/portugues/2020/10/12/criancasrepresentam-cerca-de-metade-do-numero-de-refugiados-do-mundo/. Acesso em: 12 jul. 2021.

FRANCISCO, Papa. Carta encíclica Fratelli Tutti do Santo Padre Francisco sobre a fraternidade e a amizade social. Vaticano: Libreria Editrice Vaticana, 2020. Disponível em: https://www.vatican.va/content/francesco/pt/encyclicals/documents/papafrancesco_20201003_enciclica-fratelli-tutti.html. Acesso em 12 jul. 2021.

LIMA, Mariana. Observatório do Terceiro Setor. Covid-19: O vírus pode até ser democrático, mas a Pandemia, não. 08.06.2020. Disponível em:

https://observatorio3setor.org.br/noticias/covid-19-o-virus-pode-ate-ser-democratico-masapandemia-nao/. Acesso em: 11 jul. 2021.

LUBICH, Chiara. L'Europa unita per un mondo unito. 2004.9 min 16 seg., son., color. Disponível em: https://centrochiaralubich.org/it/europa-unita-mondo-unito/. Acesso em 14 jul. 2021.

OS 17 Objetivos de Desenvolvimento Sustentável. Plataforma Agenda 2013, 2015. Disponível em: http://www.agenda2030.org.br/ods/4/. Acesso em: 15 jul.2021.

PIERRE, Luiz A.A et al. (Orgs.). Fraternidade como categoria jurídica. São Paulo: Cidade Nova, 2013. 230 p.

UNESCO. Proteção do direito à educação dos refugiados: documentos técnicos sobre política educacional. França: Organização das Nações Unidas para a Educação, a Ciência e a Cultura 2019. Disponível em: https://unesdoc.unesco.org/ark:/48223/pf0000251076_por?posInSet=1\&queryId=fdc6fa425c77-4666-b72b-cc329af020c5. Accesso em: 12 jul. 2021. 
UNHCR. Coming together: for refugee education. Geneva: The UN Refugee Agency. 2020. Disponível em: https://www.unhcr.org/publications/education/5f4f9a2b4/coming-togetherrefugee-education-education-report-2020.html. Acesso em 12 jul. 2021.

UNICEF. O progresso recuou em praticamente todos os principais indicadores relacionados à infância, afirma o UNICEF, um ano após a declaração de pandemia. 11.03.2021. Disponível em: https://www.unicef.org/brazil/comunicados-de-imprensa/oprogresso-recuou-em-praticamente-todos-os-principais-indicadores-da-infancia-um-ano-aposdeclaracao-de-pandemia. Acesso em: 10 jul. 2021.

VERONESE, Josiane Rose Petry et al. O direito e o tempo na perspectiva da construção do ser criança. In: VERONESE, J.R.P; SILVA, R.L. (Orgs.) A Criança e seus Direitos: entre violações e desafios. Porto Alegre: FI, 2019. p. 14-37. 